\title{
EFFECT OF INCIDENCE ANGLE VARYING FROM 0 RAD TO П/2 RAD AND INTENSITY OF RADIO WAVES ON THE PERFORMANCE OF A SILICON SOLAR CELL
}

\author{
Issa Zerbo ${ }^{1 *}$, Martial Zoungrana', Mamoudou Saria', \\ Adama Ouedraogo', Dieudonné Joseph Bathiebo' \\ ' Laboratory of Thermal and Renewable Energies, Department of Physics, Unit of Training and Research in Pure \\ and Applied Sciences, University Ouaga I Prof. Joseph KI-ZERBO, Burkina Faso \\ * Corresponding author'a e-mail: izerbo@hotmail.com
}

Received: 2017.09 .26

Accepted: 2017.11.01

Published: 2017.12.05

\begin{abstract}
In this work, a one dimensional approach is presented for modelling the effect of the incidence angle, varying from $0 \mathrm{rad}$ to $\pi / 2 \mathrm{rad}$, and the intensity of radio waves on the performance of a polycrystalline silicon solar cell under constant multispectral illumination. By solving the continuity equation in steady state, we derived the expression of the density of excess minority carriers, the photocurrent density, the photovoltage, the electric power and their dependence on the incidence angle and the intensity of the electromagnetic field is analyzed. Using the electric power curves versus junction dynamic velocity we determined the electric power lost at the junction, the maximum electric power and we calculated the conversion efficiency for various incidence angle and intensity of the electromagnetic field. The leakage photocurrent density, deduced from the photocurrent density curves versus junction dynamic velocity, and the electric power lost at the junction allowed us to calculate the shunt resistance of the solar cell according to the incidence angle and the intensity of the electromagnetic field. The numerical data show the negative effect of radios waves on the performance of a silicon solar cell.
\end{abstract}

Keywords: conversion efficiency, incidence angle, radio waves, shunt resistance, solar cell

\section{INTRODUCTION}

Photovoltaic solar energy is a very promising solution that can greatly contribute in solving the increasing energy demand. The performance of photovoltaic systems depends on a number of parameters such as ambient temperature, solar irradiance, sunshine duration, relative humidity, atmospheric concentrations of aerosols (harmattan dust particles for example), wind speed, wind chill and direction, rainfall, mode of installation and orientation (rooftop or ground-mounted) etc.[1, 4].

In both rural and urban areas, photovoltaic modules are sometimes installed close to telecommunication antennas as television anten- nas, radio antennas or Base Transceiver Station (BTS). But it seems that photovoltaic modules and the silicon solar cells of these photovoltaic modules are sensitive to the electromagnetic field generated by electromagnetic emission sources. So, interaction between photovoltaic modules and electromagnetic fields or radiation have to be taken into account [2].

Various researchers have used both experimental and theoretical methods to investigate the interaction between radio waves and solar cells and they arrived at different results.

Drapalik et al. [2] studied crystalline photovoltaic cells as both receivers and emitters of electromagnetic waves. As receivers, they con- 
cluded that the reception of electromagnetic radiation depends linearly on the cell area, at least at low frequencies (below $10 \mathrm{MHz}$ ). They also used two antennas, namely dipole and patch antennas to model the reception behavior of the solar cells. They concluded that the patch antenna may be used to roughly describe the reception behavior of the cells, much better compared to the dipole antenna.

Other researchers have also conducted theoretical modelling of the effect of radio waves on the properties of solar cells. Zerbo et al. used onedimensional steady state approach to study the recombination properties of silicon solar cells [10]. The electromagnetic field considered in their study was that produced by an amplitude modulation (AM) radio antenna of a given radiation power. For a given orientation of the electromagnetic field, they varied the distance between the solar cells and the radio antenna while the cells were being illuminated by a multispectral light. The study showed that the magnetic field component of the electromagnetic wave has negligible effect on the cells while its electric component influences the cells. They also observed an increase of the short-circuit photocurrent density and the leakage photocurrent density but a decrease of the open circuit voltage. In a related study, Zerbo et al. [9] studied the effect radio waves on the power output and conversion efficiency of a silicon solar cell. The study conditions were same as in [10], except that this time the cells were illuminated by monochromatic light. Their study revealed that for a given wavelength of the monochromatic light, the open circuit voltage decreases while the short circuit photocurrent density and the leakage photocurrent density are increasing as the intensity of the electromagnetic field increases. A comparative study of the influence of electromagnetic field coming from AM and FM radio antennas on the power output and conversion efficiency of a silicon solar cell has been conducted by Zerbo et al. [11]. For a given type of radio antenna, they obtained the same conclusion as for previous studies $[9,10]$ but their study revealed that the FM radio antennas which produce low values of electromagnetic field have less influence on the solar cell than AM radio antennas.

In their studies, Zerbo et al. [9-11], did not take into account the leakage photocurrent density and the related electric power to calculate the shunt resistance of solar cells exposed to radio waves.

In this work, we showed how the orientation and the intensity of radio waves can affect the efficiency of a solar cell. Firstly, we solved the continuity equation of excess minority carriers by taking into account the intensity of the electromagnetic field and its incidence angle on the solar cell before discussing their influence on the photocurrent density, the photovoltage and the electric power. Secondly, the electric power curves versus junction dynamic velocity (P-Sf) method is used to find, according to the incidence angle and the intensity of the electromagnetic field, the electric power lost at the junction and the maximum electric power which allowed us to calculate the conversion efficiency. Assuming that the open circuit electric power is lost by Joule effect at the solar cell's junction, we calculated the shunt resistance of the solar cell using the leakage photocurrent density, deduced from the photocurrent density curves versus junction dynamic velocity.

\section{THEORETICAL BACKGROUND}

This study is focused on the base region of a polycrystalline back surface field silicon solar cell (Figure 1) with the following assumptions:

- the base contribution to photoconversion is greater than that of the emitter [8].

- the p-type base is quasi-neutral (Quasi-Neutral Base assumption) so that only the junction electric field will be taken into account [6].

- the temperature effect on the performance of the solar cell is not taken into account [7].

- the solar cell is submitted to the action of a plane progressive monochromatic waves linearly polarized and propagating in the sense of the increasing $\mathrm{z}$ [9-11].

- the electromagnetic waves meet the solar cell with an incidence angle $\theta$.

- the origin of space and time is chosen at the moment when the electromagnetic waves meet the solar cell [9-11].

- the magnetic field and the electric field of a plane progressive waves are related by the relation [9-11]: $\vec{B}=\frac{\vec{e}_{z} \times \vec{E}}{c}$

- the AM antenna is isotropic and radiates a power $\mathrm{P}_{\mathrm{r}}(\mathrm{W})$ in free space, so that at a distance $r(m)$, the electric field intensity $\mathrm{E}_{0}(\mathrm{~V} / \mathrm{m})$ of the electromagnetic waves produced by the antenna is [3]: $E_{0}=\frac{1}{2 \cdot r} \cdot \sqrt{\frac{P_{r} \cdot Z_{0}}{\pi}}$ 


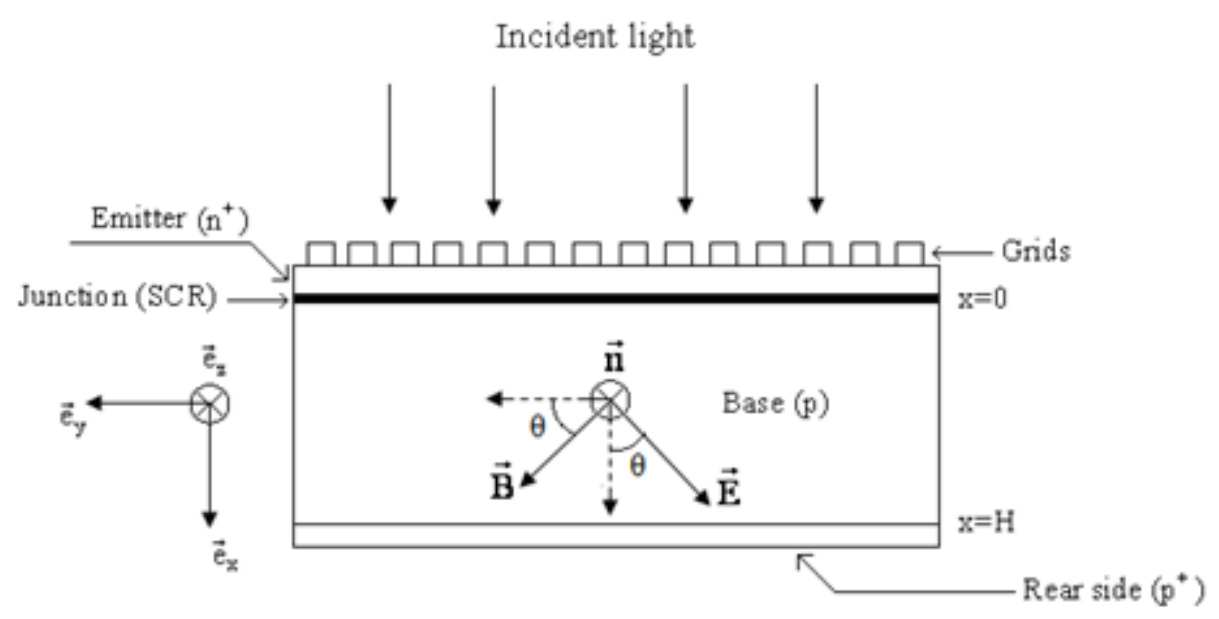

Figure 1. Silicon solar cell illuminated by multispectral light and under the influence of incidence angle of radio waves

When the solar cell represented in Figure 1 is illuminated with a multispectral light and submitted to the action of an electromagnetic field, four major phenomena occur inside it: carriers' generation, recombination, diffusion under magnetic field and drift in presence of electric and magnetic fields. In one dimensional approach and steady state condition, the continuity equation relative to the density of minority carriers (electrons) photo generated in the base region is:

$$
\begin{gathered}
\frac{\partial^{2} \delta(x)}{\partial x^{2}}+\frac{L_{E}^{*}(\theta)}{L_{n}^{* 2}(\theta)} \cdot \frac{\partial \delta(x)}{\partial x}- \\
-\frac{\delta(x)}{L_{n}^{* 2}(\theta)}+\frac{G(x)}{D_{n}^{*}(\theta)}=0
\end{gathered}
$$

In Equation (1), $L_{E}^{*}=\frac{\mu_{n}^{*} \cdot E_{0} \cdot \cos (\theta) \cdot L_{n}^{* 2}(\theta)}{D_{n}^{*}(\theta)}$ is a coefficient that characterizes drift phenomenon in the base of the solar cell. $\mu_{n}^{*}=\frac{\mu_{n}}{1+\left(\mu_{n} \cdot B_{0}\right)^{2}}$ is the electrons mobility in the magnetic field, $D_{n}^{*}(\theta)=\frac{D_{n} \cdot\left\{1+\left[\mu_{n} \cdot B_{0} \cdot \sin (\theta)\right]^{2}\right\}}{1+\left(\mu_{n} \cdot B_{0}\right)^{2}}$ and $L_{n}^{*}(\theta)$ are the electron diffusion coefficient and diffusion length in the presence of magnetic field with incidence angle.

$\delta(x)$ and $\mathrm{G}(\mathrm{x})$ are respectively the density of carriers and the optical generation rate of electrons-holes pair for a multispectral incident light.

The solution of Equation (1) which is the density of excess minority carriers is:

$$
\begin{aligned}
& \delta(x, \theta)=e^{\alpha \cdot x} \cdot\left[A_{1} \cdot \operatorname{ch}(\beta \cdot x)+\right. \\
& \left.+A_{2} \cdot \operatorname{sh}(\beta \cdot x)\right]-\sum_{i=1}^{3} K_{i} \cdot e^{-b_{i} \cdot x}
\end{aligned}
$$

where: $K_{i}=\frac{-a_{i}}{D_{n}^{*}(\theta) \cdot\left[b_{i}^{2}-\frac{1}{L_{n}^{* 2}(\theta)}-\frac{L_{E}^{*}(\theta)}{L_{n}^{* 2}(\theta)} \cdot b_{i}\right]}$

$$
\begin{aligned}
& \alpha=-\frac{L_{E}^{*}(\theta)}{2 \cdot L_{n}^{* 2}(\theta)} ; \\
& \beta=\frac{\left[L_{E}^{* 2}(\theta)+4 \cdot L_{n}^{* 2}(\theta)\right]^{1 / 2}}{2 \cdot L_{n}^{* 2}(\theta)} .
\end{aligned}
$$

The constants $\mathrm{A}_{1}$ and $\mathrm{A}_{2}$ are determined using the two boundary conditions:

- At the junction of the solar cell $(\mathrm{x}=0)$

$$
\left.D_{n}^{*}(\theta) \cdot \frac{\partial \delta(x, \theta)}{\partial x}\right)_{x=0}=S f \cdot \delta(x=0, \theta)
$$

- At the rear side of the cell solar $(\mathrm{x}=\mathrm{H})$

$$
\left.D_{n}^{*}(\theta) \cdot \frac{\partial \delta(x, \theta)}{\partial x}\right)_{x=H}=-S b \cdot \delta(x=H, \theta)
$$

$\mathrm{Sf}$ and $\mathrm{Sb}$ are respectively the junction dynamic velocity and the back surface recombination velocity. Sf is the junction dynamic velocity and it quantifies the flow of excess carriers through the junction [12]. Therefore Sf defines 
the working point of the solar cell and it is related to the external load resistance. Low values of the junction dynamic velocity (Sf tends to zero) are related to higher values of the external load resistance: the solar cell operates near the open circuit [12]. Conversely, high values of the junction dynamic velocity $\left(\mathrm{Sf} \geq 10^{6} \mathrm{~cm} \cdot \mathrm{s}^{-1}\right)$ are related to low values of the external load resistance: the solar cell operates near the short circuit [12].

The expression of the photocurrent density is derive from the density of the excess minority carriers using Fick's law at the solar cell junction:

$$
\begin{gathered}
\operatorname{Jph}(S f, \theta)=q \cdot\left[D_{n}^{*}(\theta) \cdot \frac{\partial \delta(x, S f, \theta)}{\partial x}\right)_{x=0}+ \\
\left.+\mu_{n}^{*} \cdot E_{0} \cdot \cos (\theta) \cdot \delta(x=0, S f, \theta)\right]
\end{gathered}
$$

where: $q$ is the electronic charge.

Using Equation (3.a), the previous equation can be written as:

$$
\begin{aligned}
\operatorname{Jph}(S f, \theta) & =q \cdot\left[S f+\mu_{n}^{*} \cdot E_{0} \cdot \cos (\theta)\right] . \\
& \cdot \delta(x=0, S f, \theta)
\end{aligned}
$$

The expression of the photovoltage across the solar cell junction is expressed using Boltzmann's relation:

$$
\operatorname{Vph}(S f, \theta)=V_{T} \cdot \ln \left(N_{B} \frac{\delta(x=0, S f, \theta)}{n_{i}^{2}}+1\right)
$$

where: $\mathrm{V}_{\mathrm{T}}$ is the thermal voltage,

$\mathrm{N}_{\mathrm{B}}$ the base doping density and $\mathrm{n}_{\mathrm{i}}$ the electrons' intrinsic concentration at thermodynamic equilibrium.

The expression of the electric power delivered by the solar cell to an external circuit is:

$$
P(S f, \theta)=V p h(S f, \theta) \cdot J p h(S f, \theta)
$$

Knowing the maximum electric power delivered by the solar cell, the solar cell conversion efficiency is calculated using Equation (7):

$$
\eta(\theta)=\frac{P(S f, \theta)_{\max }}{P_{i n c}}
$$

$P_{\text {inc }}=100 \mathrm{~mW} / \mathrm{cm}^{2}$ is the power of the flux of the incident light in Air Mass 1.5 standard conditions.

\section{RESULTS AND DISCUSSION}

Using the mathematical formulation above, the simulations are conducted for various incidence angle of the electromagnetic field, various intensity of the electromagnetic field and various operating conditions through the dynamic junction velocity.

The modelling of the effect of the incidence angle is made assuming that the power of radiation of the AM radio antenna is $\mathrm{Pr}$ $=2 \mathrm{MW}$ in free space and the distance between the solar cell and the radio antenna is $\mathrm{r}=50 \mathrm{~m}$. Therefore the intensity of the electromagnetic field is: $\mathrm{E}_{0}=154.9 \mathrm{~V} / \mathrm{m}$ and $\mathrm{B}_{0}=$ $5.162 \times 10^{-7} \mathrm{~T}$. For the modelling of the effect of the intensity of the electromagnetic field, $\theta$ $=0 \mathrm{rad}$ is used as incidence angle.

The intensities of the electromagnetic field according to the distance between the solar cell and the radio antenna are given in Table 1 [9].

\section{Photocurrent density}

\section{Effect of the incidence angle of the electromagnetic field}

The curves of photocurrent density versus junction dynamic velocity are plotted in Figure 2 for various incidence angle of the electromagnetic field.

The curves in Figure 2 show that, for incidence angle varying from $\theta=0 \mathrm{rad}$ to $\theta=\pi / 2 \mathrm{rad}$, each one of the curves of photocurrent density is in concord with the traditional curve of photocur-

Table 1. Intensity of the electromagnetic field for various distance solar cell-antenna.

\begin{tabular}{|c|c|c|c|c|c|}
\hline Distance $r(m)$ & 50 & 100 & 500 & 1000 & $r=+\infty 0$ \\
\hline $\mathrm{E}_{0}(\mathrm{~V} / \mathrm{m})$ & 154.9 & 77.4 & 15.5 & 7.7 & 0 \\
\hline $\mathrm{B}_{0}(\mathrm{~T})$ & $5.162 \times 10^{-7}$ & $2.581 \times 10^{-7}$ & $5.162 \times 10^{-8}$ & $2.581 \times 10^{-8}$ & 0 \\
\hline
\end{tabular}




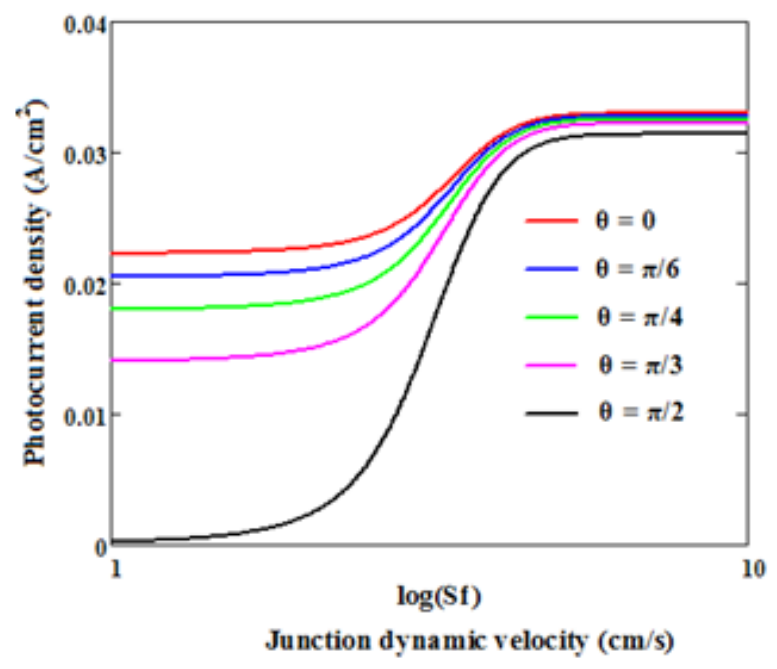

Figure 2. Photocurrent density versus junction dynamic velocity for various incidence angle $(\mathrm{L}=0.02$ $\left.\mathrm{cm} ; \mathrm{H}=0.03 \mathrm{~cm} ; \mathrm{D}=26 \mathrm{~cm}^{2} / \mathrm{s} ; \mu \mathrm{n}=1000 \mathrm{~cm}^{2} / \mathrm{V} . \mathrm{s}\right)$

rent density of a solar cell under electromagnetic field. Except the curve of $\theta=\pi / 2 \mathrm{rad}$, for which the electromagnetic field has no effect, we notice an open circuit photocurrent density or leakage photocurrent density. This leakage photocurrent density decreases with the increase of the incidence angle. For an incidence angle varying from $\theta=0 \mathrm{rad}$ to $\theta=\pi / 2 \mathrm{rad}, \cos (\theta) \succ 0$, the photocurrent density at the junction of the solar cell is the sum of the diffusion current density and the drift current density. Therefore the drift current density is responsible of the leakage photocurrent density in open circuit.

\section{Effect of the intensity of the electromagnetic field}

The curves of photocurrent density versus junction dynamic for various intensity of the electromagnetic field are plotted in Figure 3.

The curves in Figure 3 show that the open circuit photocurrent density or leakage photocurrent density decreases strongly while the short circuit photocurrent density decrease slightly with the increase of the distance. The increase of the distance corresponds to a decrease of the intensity of the electromagnetic field. Therefore, the presence of an electromagnetic field near a solar cell causes a migration of carriers through the junction of an ideal solar cell. In fact, the leakage photocurrent density is negligible at the junction of an ideal solar cell because of the high value of its shunt resistance. The migration of the carriers through the junction creates a Joule effect for high intensity of electromagnetic field.

\section{Open circuit photovoltage}

The results of previous work [9-11] have showed that the effects of electromagnetic field intensity are more noticeable in open circuit. Therefore, the modelling of the effect of the incidence angle and the intensity of the electromagnetic field is focused on the open circuit photovoltage.

\section{Effect of the incidence angle of the electromagnetic field}

In Figure 4, we plotted the curves of the open circuit photovoltage versus incidence angle of the electromagnetic field.

The open circuit voltage increases while the incidence angle increases from $\theta=0$ rad to $\theta=\pi / 2$ $\mathrm{rad}$. In fact, when the incidence angle increase the effect of the electromagnetic field on the solar cell decreases. The migration of the carriers through the junction, that gives rise to a leakage photocurrent density, decreases resulting in an increase of the open circuit voltage.

\section{Effect of the intensity of the electromagnetic field}

We plotted in Figure 5, the curves of the open circuit photovoltage versus the distance between the solar cell and the antenna which corresponds also to the intensity of the electromagnetic field.

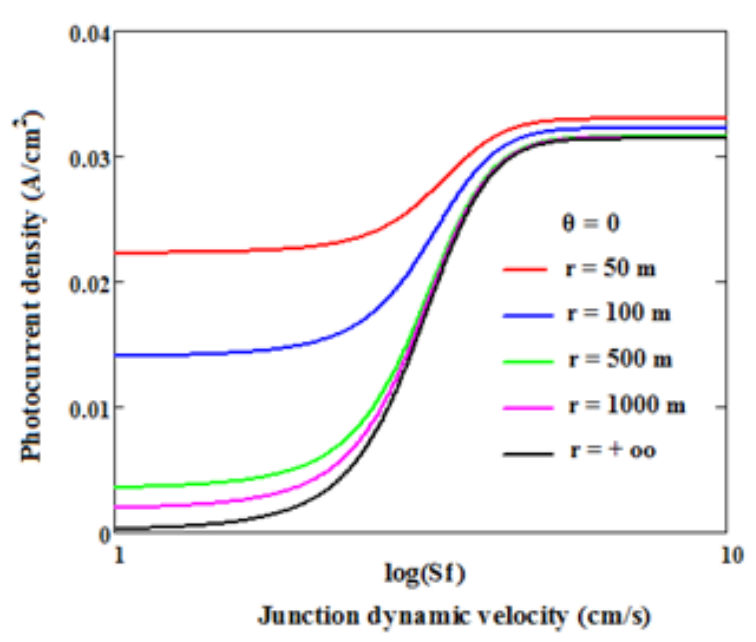

Figure 3. Photocurrent density versus junction dynamic velocity for various distance $(\mathrm{L}=0.02 \mathrm{~cm} ; \mathrm{H}=$ $0.03 \mathrm{~cm} ; \mathrm{D}=26 \mathrm{~cm}^{2} / \mathrm{s} ; \mu \mathrm{n}=1000 \mathrm{~cm}^{2} /$ V.s $)$. 


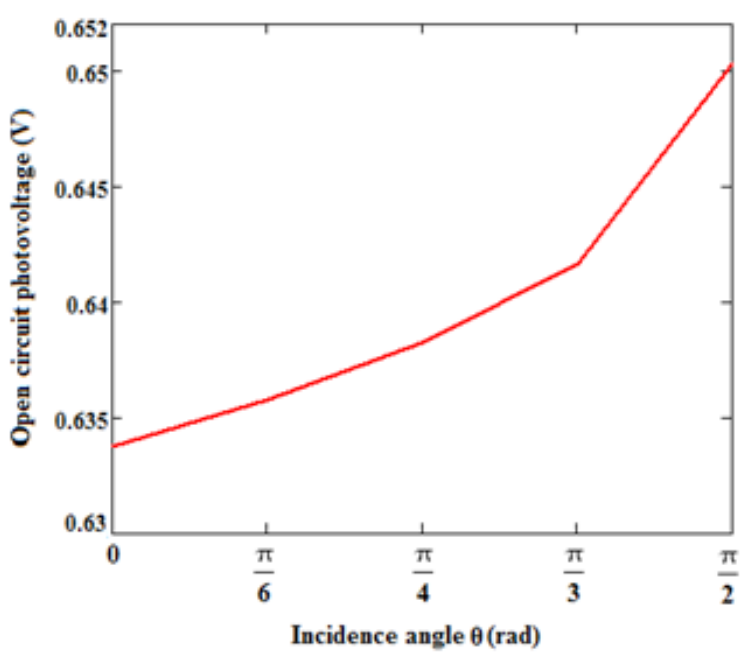

Figure 4. Open circuit photovoltage for different incidence angle $(\mathrm{L}=0.02 \mathrm{~cm} ; \mathrm{H}=0.03 \mathrm{~cm}$; $\mathrm{D}=26 \mathrm{~cm}^{2} / \mathrm{s} ; \mu \mathrm{n}=1000 \mathrm{~cm}^{2} / \mathrm{V} . \mathrm{s}$ )

The curves in Figure 5 show that the open circuit voltage decreases while the distance decreases and that corresponds to an increase of the intensity of the electromagnetic field. Indeed, the existence of the leakage photocurrent density in open circuit, which increases with the decrease of the distance, is responsible for the decrease of the open circuit voltage because some carriers cross the junction resulting in a reduction of the quantity of carriers stocked at the junction.

\section{Electric power}

\section{Effect of the incidence angle of the electromagnetic field}

The curves of electric power versus junction dynamic for various incidence angle of the electromagnetic field are plotted in Figure 6.

The curves in Figure 6 show that, for an incidence angle varying from $\theta=0$ rad to $\theta=\pi / 2 \mathrm{rad}$, the electric power is not null in open circuit while for $\theta=\pi / 2 \mathrm{rad}$ the electric power in open circuit is null. For a given distance or intensity of the electromagnetic field, the electric power in open circuit and the maximum electric power are decreasing function of the incidence angle. Thus, the leakage photocurrent density gives rise to the electric power in open circuit. This electric power is lost at the junction by Joule effect. It is well known that, in the Shockley five-parameter model of a solar cell, a shunt resistance represents the leakage current along the edges of the solar cell [5].Therefore, the open circuit electric power is

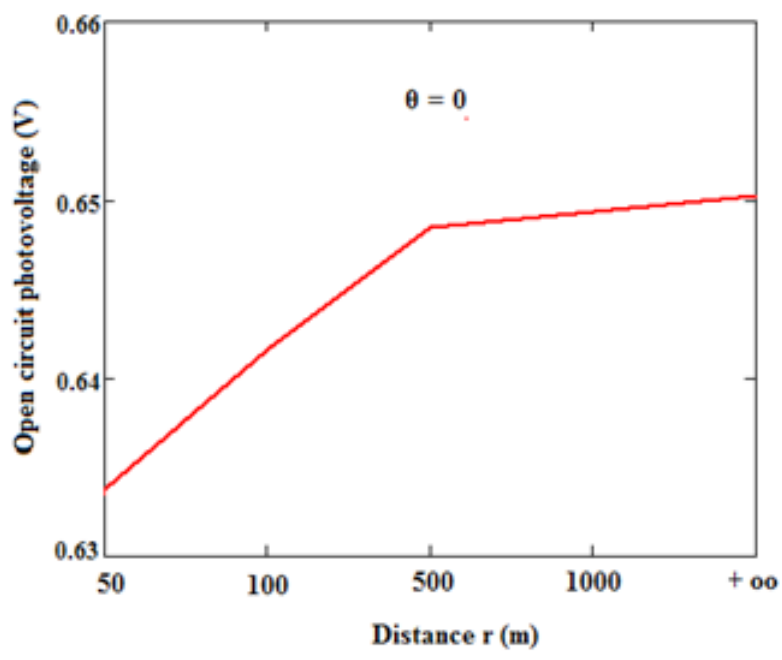

Figure 5. Open circuit photovoltage for various distance $\left(\mathrm{L}=0.02 \mathrm{~cm} ; \mathrm{H}=0.03 \mathrm{~cm} ; \mathrm{D}=26 \mathrm{~cm}^{2} / \mathrm{s}\right.$; $\left.\mu \mathrm{n}=1000 \mathrm{~cm}^{2} / \mathrm{V} . \mathrm{s}\right)$

lost in this shunt resistance by Joule effect. Thus, knowing the electric power lost at the solar cell's junction and the leakage photocurrent density we calculated the shunt resistance using Equation (8):

$$
R_{s h}=\frac{P_{o c}}{J p h_{o c}^{2}}
$$

In Table 2, we give the values of the electric power and photocurrent density in open circuit, the maximum electric power, the conversion efficiency and the shunt resistance according to the incidence angle of the electromagnetic field.

The results of Table 2 show that the maximum electric power, the conversion efficiency,

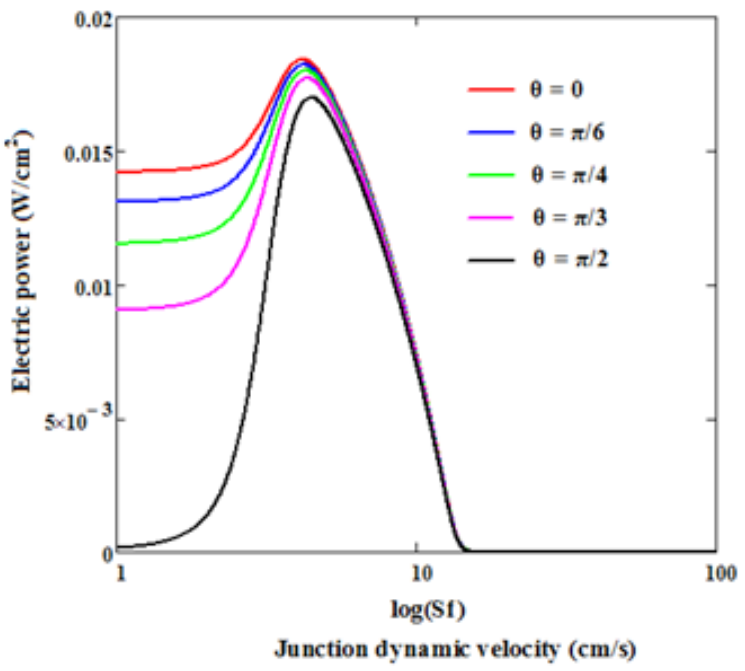

Figure 6. Electric power versus junction dynamic velocity for various incidence angle $(\mathrm{L}=0.02 \mathrm{~cm} ; \mathrm{H}$ $\left.=0.03 \mathrm{~cm} ; \mathrm{D}=26 \mathrm{~cm}^{2} / \mathrm{s} ; \mu \mathrm{n}=1000 \mathrm{~cm}^{2} / \mathrm{V} . \mathrm{s}\right)$. 
Table 2. Conversion efficiency and shunt resistance for various incidence angle.

\begin{tabular}{|c|c|c|c|c|c|}
\hline$\theta(\mathrm{rad})$ & 0 & $\pi / 6$ & $\pi / 4$ & $\pi / 3$ & $\pi / 2$ \\
\hline $\mathrm{P}_{\max }\left(\mathrm{mW} / \mathrm{cm}^{2}\right)$ & 18.411 & 18.23 & 18.01 & 17.716 & 17 \\
\hline Efficiency $\eta(\%)$ & 18.411 & 18.23 & 18.01 & 17.716 & 17 \\
\hline $\mathrm{P}_{\mathrm{oc}}\left(\mathrm{mW} / \mathrm{cm}^{2}\right)$ & 14.202 & 13.09 & 11.53 & 9.0364 & 0.15092 \\
\hline $\mathrm{Jph}_{\mathrm{oc}}\left(\mathrm{mA} / \mathrm{cm}^{2}\right)$ & 22.272 & 20.477 & 17.987 & 14.039 & 0.22691 \\
\hline $\mathrm{R}_{\mathrm{sh}}\left(\Omega . \mathrm{cm}^{2}\right)$ & 28.631 & 31.218 & 35.638 & 45.848 & $2.931 \times 10^{3}$ \\
\hline
\end{tabular}

the open circuit electric power (electric power lost at the solar cell's junction) and the leakage photocurrent density decrease with the increase of the incidence angle of the electromagnetic field while the shunt resistance increases. The increase of the incidence angle of the electromagnetic field corresponds to a decrease of the effect of the electromagnetic field on the solar cell. The increase of the shunt resistance of the solar cell contributes to improve the quality of the junction of the solar cell and consequently a reduction of both the leakage photocurrent density and the electric power lost at the junction

\section{Effect of the intensity of the electromagnetic field}

In Figure 7, we plot the curves of electric power versus junction dynamic for various intensity of the electromagnetic field or distance.

The curves in Figure 7 show that, for a given incidence angle $\theta=0 \mathrm{rad}$, the electric power in open circuit and the maximum electric power increase when the distance between the solar cell and the radio antenna decreases (the intensity of

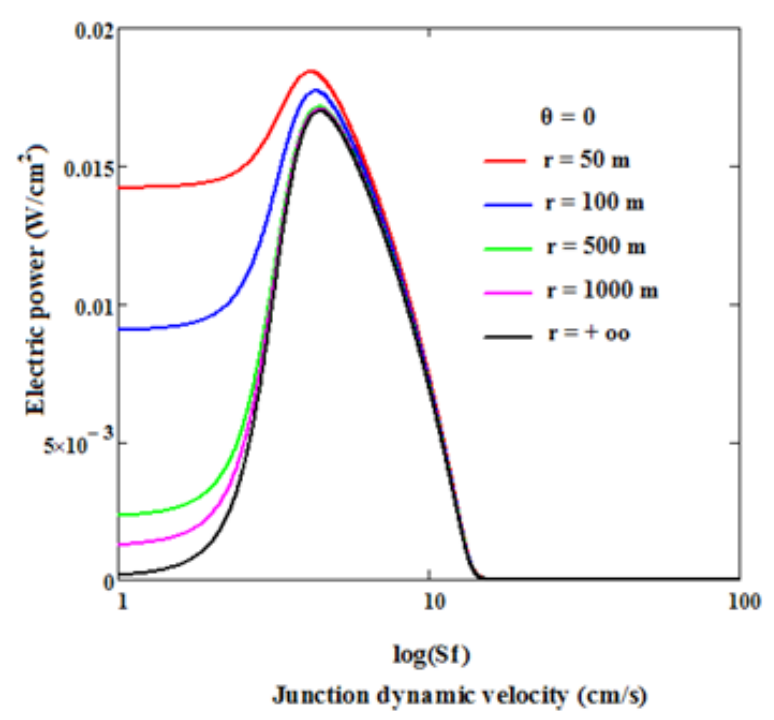

Figure 7. Electric power versus junction dynamic velocity for various distance $(\mathrm{L}=0.02 \mathrm{~cm} ; \mathrm{H}=0.03$ $\left.\mathrm{cm} ; \mathrm{D}=26 \mathrm{~cm}^{2} / \mathrm{s} ; \mu \mathrm{n}=1000 \mathrm{~cm}^{2} / \mathrm{V} . \mathrm{s}\right)$. the electromagnetic field increases). The electric power that appears in open circuit is not used by an external circuit but it is lost by Joule effect at the junction.

In Table 3, we give the values of the electric power and photocurrent density in open circuit, the maximum electric power, the conversion efficiency and the shunt resistance according to the distance which is inversely proportional to the intensity of the electromagnetic field.

The results of Table 3 show that the maximum electric power, the conversion efficiency, the open circuit electric power and the leakage photocurrent density decrease with the increase of the distance between the solar cell and the radio antenna while the shunt resistance increases. The increase of the distance between the solar cell and the radio antenna corresponds to a decrease of the intensity of the electromagnetic field.

\section{CONCLUSION}

The performance of a silicon solar cell under the influence of radio waves has been investigated.

From a one-dimensional model, we pointed out the effects of the incidence angle and intensity of radio waves on the conversion efficiency and shunt resistance of a polycrystalline silicon solar cell.

It appeared in this work that, for an incidence varying from $\theta=0 \mathrm{rad}$ to $\theta=\pi / 2 \mathrm{rad}, \cos (\theta) \succ 0$, the photocurrent density at the junction of the solar cell is the sum of the diffusion current density and the drift current density. Therefore in open circuit the drift current density, due to the migration of the carriers through the junction, gives rise to a leakage photocurrent density and an electric power lost at the junction by Joule effect. For a given intensity of the electromagnetic field, the open circuit electric power, the leakage photocurrent density, the maximum electric power and the conversion efficiency decrease with the increase of the incidence angle of the electromagnetic field while the shunt resistance increases. 
Table 3. Conversion efficiency and shunt resistance for various incidence angle.

\begin{tabular}{|c|c|c|c|c|c|}
\hline $\mathrm{r}(\mathrm{m})$ & 50 & 100 & 500 & 1000 & $+\infty$ \\
\hline $\mathrm{P}_{\max }\left(\mathrm{mW} / \mathrm{cm}^{2}\right)$ & 18.411 & 17.716 & 17.136 & 17.063 & 17.00 \\
\hline Efficiency $\eta(\%)$ & 18.411 & 17.716 & 17.136 & 17.063 & 17.00 \\
\hline $\mathrm{P}_{\mathrm{oc}}\left(\mathrm{mW} / \mathrm{cm}^{2}\right)$ & 14.201 & 9.0364 & 2.3132 & 1.2578 & 0.15889 \\
\hline $\mathrm{Jph}_{\mathrm{oc}}\left(\mathrm{mA} / \mathrm{cm}^{2}\right)$ & 22.272 & 14.039 & 3.5655 & 1.9368 & 0.24442 \\
\hline $\mathrm{R}_{\mathrm{sh}}\left(\Omega . \mathrm{cm}^{2}\right)$ & 28.629 & 45.848 & 181.958 & 335.307 & $2.66 \times 10^{3}$ \\
\hline
\end{tabular}

This study also showed that for an incidence angle such as $\theta=0 \mathrm{rad}$, the leakage photocurrent density and the open circuit electric power decrease strongly until their cancellation with the increase of the distance between the solar cell and the radio antenna. The numerical data are evidence of a decrease in the maximum electric power and the conversion efficiency with the increase of the distance between the solar cell and the radio antenna while the shunt resistance increases.

The solar cell studied in this article is an ideal solar cell and so the leakage photocurrent density and the open circuit electric power at the junction interface are neglected resulting in a high value of the shunt resistance. Consequently, the presence of a leakage photocurrent density and an open circuit electric power at the junction interface leads to a reduction of the shunt resistance and a Joule effect. The decrease of the shunt resistance and the Joule effect affect the quality of the junction of a solar cell and so its working. Therefore, solar cells have to be far from radio antennas or telecommunication antennas which are able to create strong electromagnetic fields.

\section{Acknowledgements}

The authors are grateful to International Science Program (ISP) for supporting their research group (energy and environment) and allowing them to conduct this work.

\section{REFERENCES}

1. Dia F., Mbengue N., Diagne M., Niasse O. A., Ba B. and Séne C. Contribution to the study of the degradation of modules PV in the tropical latitudes: case of Senegal. Research Journal of Applied Sciences, Engineering and Technology, 12(4), 2016, 427-438.

2. Drapalik M., Schmid J., Kancsar E., Schlosser V. and Klinger G. A study of the antenna effect of photovoltaic. International Conference on Renewable Energies and Power Quality (ICREPQ'10), Granada, Spain 2010.
3. Freyer U. Nachrichten-Uebertragungstechnik, Carl Hanser, 1994.

4. Koffi H. A., Kakane V. C. K., Kuditcher A., Hugues A. F., Adeleye M. B. and Amuzu J. K. A. Seasonal variations in the operating temperature of silicon solar panels in southern Ghana. African Journal of Science, Technology, Innovation and Development, 7(6), 2015, 485-490.

5. Koffi H. A., Kuditcher A., Kakane V. C. K., Armah E. A., Yankson A. A. and Amuzu J. K. A. (2015) The Shockley five-parameter model of a silicon solar cell: A short note. African Journal of Science, Technology, Innovation and Development, 7(6), 491-494.

6. Misiakos K., Wang C. H., Neugroschel A. and Lindholm F. A. Simultaneous Extraction of Minority-Carrier Parameters in Crystalline Semiconductors by Lateral Photocurrent. Journal of Applied Physics, 67(1), 1990, 321-333.

7. Sane M., Sahin G., Barro F. I. and Maiga A. S. Incidence angle and spectral effects on vertical junction silicon solar cell capacitance. Turkish Journal of Physics, 38(2), 2014, 221-227.

8. Sissoko G., Corréa A., Nanema E., Diarra M. N., Ndiaye A. L. and Adj A. Recombination parameters measurement in silicon double sided surface field solar cell. Proc. of World Renewable Energy Congress, Florence, Italy 1998, 1856-1859.

9. Zerbo I., Zoungrana M., Ouedraogo A., Bruno K., Zouma B. and Bathiebo D. J. Influence of electromagnetic waves produced by an amplitude modulation radio antenna on the electric power delivered by a silicon solar cell. Global Journal of Pure and Applied Sciences, 20, 2014, 139-148.

10. Zerbo I., Zoungrana M., Seré A. D., Ouedraogo F., Sam R., Zouma B. and Zougmoré F. Influence d'une onde électromagnétique sur une photopile au silicium sous éclairement multispectral en régime statique. Revue des Energies Renouvelables, 14(3), 2011, 517-532.

11. Zerbo I., Zoungrana M., Seré A. D. and Zougmoré F. Silicon solar cell under electromagnetic wave in steady state: effect of the telecommunication source's power of radiation. IOP Conference Series: Materials Science and Engineering, 29, 2012, 012019.

12. Zerbo I., Zoungrana M., Sourabié I., Ouedraogo A., Zouma B. and Bathiebo D. J. External magnetic field effect on bifacial silicon solar cell's electric power and conversion efficiency. Turkish Journal of Physics, 39(3), 2015, 288-294. 